\title{
Polar Residues in the Second Transmembrane Domain of the Rat P2X2 Receptor That Affect Spontaneous Gating, Unitary Conductance, and Rectification
}

\author{
Lishuang Cao, Helen E. Broomhead, Mark T. Young, and R. Alan North \\ Faculty of Medical and Human Sciences, and Faculty of Life Sciences, University of Manchester, Manchester M13 9PL, United Kingdom
}

\begin{abstract}
Membrane ion channels activated by extracellular ATP (P2X receptors) are widely distributed in the nervous system. Their molecular architecture is fundamentally distinct from that of the nicotinic or glutamate receptor families. We have measured single-channel currents, spontaneous gating, and rectification of rat P2X2 receptor in which polar and charged residues of the second transmembrane domain (TM2) were systematically probed by mutagenesis. The results suggest that $\mathrm{Asn}^{333}$ and $\mathrm{Asp}^{349}$ lie respectively in external and internal vestibules. Substitutions at $\mathrm{Asn}^{333}, \mathrm{Thr}^{336}$, and $\mathrm{Ser}^{340}$ were particularly likely to cause spontaneously active channels. At $\mathrm{Thr}^{336}$, $\mathrm{Thr}^{339}$, and $\mathrm{Ser}^{340}$, the introduction of positive charge (Arg, Lys, or His, or Cys followed by treatment with 2-aminoethyl methanethiosulphonate) greatly enhanced outward currents, suggesting that side-chains of these three residues are exposed in the permeation pathway of the open channel. These functional findings are interpreted in the context of the recently reported $3.1 \AA$ crystal structure of the zebrafish P2X4.1 receptor in the closed state. They imply that the gate is formed by residues $\mathrm{Asn}^{333}$ to $\mathrm{Thr}^{339}$ and that channel opening involves a counter-clockwise rotation and separation of the TM2 helices.
\end{abstract}

\section{Introduction}

P2X receptors are trimeric membrane proteins (Nicke et al., 1998; North, 2002; Khakh and North, 2006). Each monomer has an ectodomain of $\sim 280$ aa and two transmembrane domains: the $\mathrm{N}$ termini and $\mathrm{C}$ termini are intracellular (North, 2002). When ATP binds to the extracellular aspect of the receptor, a permeation pathway opens through the membrane that allows the passage of small cations. Sustained application of ATP can cause the channel to become permeant to large cations such as $\mathrm{N}$-methylD-glucamine (Surprenant et al., 1996; Khakh et al., 1999; Virginio et al., 1999; Jiang et al., 2005).

Our understanding of the molecular operation of $\mathrm{P} 2 \mathrm{X}$ receptors is based mostly on inferences made from studying the biophysical properties of channels with amino acids modified by mutagenesis. Both the first and second transmembrane domains have been systematically targeted for replacement of each residue by tryptophan (Silberberg et al., 2005), alanine (Li et al., 2004), or cysteine (Rassendren et al., 1997; Egan et al., 1998; Li et al., 2008). Channel function is generally retained with such single-point substitutions. The sensitivity to ATP is often increased or de-

\footnotetext{
Received Sept. 6, 2009; revised Sept. 29, 2009; accepted 0ct. 5, 2009.

This work was supported by The Wellcome Trust. We thank Kyriaki Dossi and Lara Bragg for tissue culture. We are grateful to Fred Sachs of State University of New York for advice on single-channel methodology and interpretation. Correspondence should be addressed to R. Alan North, Michael Smith Building, University of Manchester, Oxford Road, Manchester M13 9PL, UK. E-mail: r.a.north@manchester.ac.uk.

L. Cao's present address: Pain Research Unit, Pfizer Global Research and Development, Ramsgate Road, Sandwich, Kent CT13 9NJ, UK.

H. E. Broomhead's present address: Department of Biochemistry, University of Cambridge, Sanger Building, 80 Tennis Court Road, Cambridge CB2 1GA, UK.

M. T. Young's present address: School of Biosciences, Cardiff University, Cardiff CF103AX, UK. DOI:10.1523/JNEUROSCI.4403-09.2009

Copyright $\odot 2009$ Society for Neuroscience $\quad 0270-6474 / 09 / 2914257-08 \$ 15.00 / 0$
}

creased, or the relative permeability of the channel to calcium ions $\left(\mathrm{P}_{\mathrm{Ca}} / \mathrm{P}_{\mathrm{Na}}\right)$ may be altered. The experiments with tryptophan (on rat $\mathrm{P} 2 \mathrm{X} 4$ receptors) suggest that the outer half of the second transmembrane domain (TM2) plays a particular role in the structural rearrangements that accompany channel opening, whereas the inner region of TM2 is a tightly packed structure that does not tolerate substitutions with such a bulky side-chain (Silberberg et al., 2005). The results of the alanine scanning (on rat $\mathrm{P} 2 \mathrm{X} 2$ receptors) were interpreted to suggest that the central part of TM2 (Leu ${ }^{338}$ to Ser ${ }^{345}$ ) was probably not an ordered helix and might contribute to the "gate" (Li et al., 2004). This was consistent with an earlier observation that a cysteine introduced at this position $\left(\mathrm{Gly}^{342}\right)$ is reactive to thiolates applied from either side of the membrane (Egan et al., 1998). It is also consistent with studies showing that polar residues near this position influence the relative calcium permeability (Migita et al., 2001).

Three considerations prompted the present study. First, previous approaches had often not distinguished effects on gating from effects on the permeation. We have now made singlechannel recordings for mutated channels. Second, sequences of P2X receptors from simple eukaryotes have become available, several of are known to function as ATP-gated channels. These sequences (Fig. 1) show poor absolute conservation of residues through TM2 (note $\mathrm{Gly}^{342}$ and $\mathrm{Asp}^{349}$ ) but strong conservation according to size and/or polarity. Third, the consensus interpretation from previous work suggested that polar side-chains in TM2 were more likely to be involved in the conformational rearrangements of gating or in the permeation process.

After these experiments were concluded, a report appeared describing the crystal structure of the zebrafish P2X4.1 receptor 
$\begin{array}{llllllllllll}1 & 2 & 3 & 4 & 5 & 7 & \mathrm{Sm} & \mathrm{Dd} & \mathrm{Ot} & \mathrm{Mb} & \mathrm{z} f 4\end{array}$

\begin{tabular}{|c|c|c|c|c|c|c|c|c|c|c|}
\hline 328 & $I$ & $I$ & $I$ & I & I & $I$ & L & $\mathrm{Q}$ & L & V \\
\hline 329 & $\mathbf{P}$ & P & $\mathbf{P}$ & $\mathbf{P}$ & $\mathbf{P}$ & Q & $\mathbf{P}$ & $\mathrm{T}$ & $\mathrm{T}$ & $\mathbf{P}$ \\
\hline 330 & $\mathrm{~T}$ & (ก) & $\mathrm{T}$ & $\mathrm{T}$ & $\mathrm{T}$ & L & L & $\mathrm{L}$ & L & I \\
\hline 31 & $\mathbf{M}$ & T & I & $\mathbf{M}$ & V & V & $T$ & I & $\mathbf{S}$ & I \\
\hline 332 & $\mathrm{~T}$ & & I & $I$ & $I$ & V & M & L & $\mathrm{T}$ & 7 \\
\hline 33 & $\mathbf{T}$ & (N) & $\mathbf{S}$ & $\mathbf{N}$ & $\mathbf{N}$ & $\mathbf{Y}$ & $\mathbf{N}$ & $\mathbf{T}$ & $\mathbf{T}$ & A \\
\hline 34 & $I$ & L & $\mathrm{S}$ & $\mathrm{V}$ & $I$ & $I$ & I & $\mathrm{L}$ & V & L \\
\hline 35 & G & A & $\mathbf{V}$ & $\mathbf{G}$ & $\mathbf{G}$ & G & G & $\mathbf{V}$ & G & $\mathbf{G}$ \\
\hline 36 & $S$ & (T) & A & $S$ & $\mathrm{~S}$ & S & $S$ & S & A & $\mathrm{S}$ \\
\hline 37 & $\mathbf{G}$ & & A & G & G & $\mathrm{T}$ & G & $\mathbf{G}$ & G & G \\
\hline 338 & $I$ & $\mathrm{I}$ & $F$ & $\mathrm{~L}$ & $\mathrm{~L}$ & L & L & L & V & I \\
\hline 3 & G & (T) & $\mathbf{T}$ & $\mathbf{A}$ & A & $\mathbf{S}$ & A & G & A & $\mathbf{G}$ \\
\hline 340 & I & (S) & $S$ & L & $\mathrm{L}$ & $Y$ & $\mathrm{~L}$ & L & $\mathrm{F}$ & $\mathrm{L}$ \\
\hline 41 & $F$ & & V & $\mathrm{I}$ & $\bar{M}$ & $F$ & $\bar{I}$ & L & L & I \\
\hline 342 & G & (G) & G & G & G & G & G & A & G & $\mathrm{G}$ \\
\hline 34 & v & & $\mathbf{V}$ & $\mathbf{V}$ & A & L & I & $\mathbf{V}$ & $I$ & L \\
\hline 344 & A & (G) & G & A & G & A & A & A & $\mathrm{A}$ & A \\
\hline 4 & $T$ & (S) & $\mathrm{T}$ & $\mathbf{T}$ & A & $\mathrm{T}$ & P & $\mathrm{T}$ & $\mathbf{S}$ & T \\
\hline 34 & V & $\mathrm{F}$ & $\mathrm{V}$ & $\mathrm{V}$ & $F$ & V & $\mathrm{T}$ & $\mathrm{T}$ & L & V \\
\hline 47 & L & $\stackrel{I}{ }$ & 工 & I & $\mathbf{F}$ & C & V & $\mathbf{V}$ & V & I \\
\hline 348 & $\mathrm{C}$ & (C) & $\mathrm{C}$ & $\mathrm{C}$ & C & $I$ & C & V & V & A \\
\hline 34 & D & (D) & D & D & D & D & D & D & $\mathbf{N}$ & D \\
\hline 350 & L & W & I & $\mathrm{V}$ & $\mathrm{L}$ & L & $I$ & $\mathrm{Q}$ & A & L \\
\hline 351 & L & $I$ & I & $I$ & $\mathbf{V}$ & $I$ & $I$ & L & V & 工 \\
\hline & $\mathrm{L}$ & $\mathrm{L}$ & $\mathrm{L}$ & $\mathrm{V}$ & $\mathrm{L}$ & $I$ & A & A & M & $\mathrm{V}$ \\
\hline & L & 工 & 工 & 工 & $I$ & $\mathbf{N}$ & I & $I$ & M & $\mathbf{T}$ \\
\hline
\end{tabular}

Figure 1. Sequences of the second transmembrane domain of $\mathrm{P} 2 \mathrm{X}$ receptors. Sequence comparisons among six rat $P 2 X$ receptors, four invertebrate receptors, and one zebrafish receptor, all of which form functional ATP-gated channels. 1, P2X1 (accession P47824); 2, P2X2 (P49653); 3, P2X3 (P49654); 4, P2X4 (P51577); 5, P2X5 (51578); 7, P2X7 (Q64663); Sm, Schistosoma mansoni (CAH04147); Dd, Dictyostelium discoideum (ABS88293); Ot, Ostreococcus tauri (CAL54489); Mb, Monosiga brevicollis (XP_001743535); zf4, Zebrafish P2X4.1 (AF317643). Residues mutated in this study are circled.

at $3.1 \AA$ resolution (Kawate et al., 2009). This has provided the opportunity for the results to be discussed in the context of that structure.

\section{Materials and Methods}

Molecular and cell biology. Mutations in rat $\mathrm{P} 2 \mathrm{X} 2$ receptors were made as described previously (Cao et al., 2007; Rassendren et al., 1997; Jiang et al., 2001). The wild-type and mutant P2X2 subunits were transiently coexpressed together with GFP vector in HEK 293 cells (by Lipofectamine 2000; Invitrogen), using $0.1 \mu \mathrm{g}$ P2X2 receptor cDNA and $1 \mu \mathrm{g}$ GFP DNA. Transfected cells were seeded on glass coverslips coated with poly-L-lysine.

Western blot and surface expression. Cell-surface protein was labeled using EZ-link sulfo-NHS-LC-biotin (Pierce). Confluent cells (one 35 $\mathrm{mm}$ culture dish per sample) were washed three times in PBS, $\mathrm{pH} 8.0$, and incubated in $1 \mathrm{ml} \mathrm{PBS}$ containing $0.5 \mathrm{mg} / \mathrm{ml}$ biotin for $30 \mathrm{~min}$ at $4^{\circ} \mathrm{C}$. After washing, cells were centrifuged and pellets lysed in PBS containing $2 \%$ Triton X-100 and antiproteases (complete-EDTA; Roche) for $1 \mathrm{~h}$ at $4^{\circ} \mathrm{C}$. After centrifugation $(16000 \times \mathrm{g}, 2 \mathrm{~min})$ to remove debris, total protein samples were removed and assayed for protein content using a protein assay kit (Bio-Rad). Biotinylated surface protein in the cell lysate was bound to immuno-pure immobilized streptavidin beads (Pierce) overnight at $4^{\circ} \mathrm{C}$. After washing in $0.2 \%$ Triton X-100, SDS-PAGE sample buffer was added, and the samples were boiled $\left(5 \mathrm{~min}, 100^{\circ} \mathrm{C}\right)$ to release cell-surface protein. Samples were separated on $4-12 \% \mathrm{Nu}-$ PAGE gels (Invitrogen) and transferred to polyvinylidene fluoride membranes. Western blotting was performed according to standard protocols, and proteins were visualized using anti-Glu-Tyr-Met-ProMet-Glu primary antibody (Universal Biologicals) and HRP-conjugated secondary antibody (both at 1:5000 dilution), followed by detection us- ing the ECL-plus kit (GE Healthcare) and Kodak BioMax MS film. Band densities were quantified using GeneSnap/GeneTools software (Syngene), and densities were compared using ANOVA.

Electrophysiological recording. Recordings were made at room temperature $24-72 \mathrm{~h}$ after transfection, using outside-out and whole-cell configurations of the patch-clamp technique. As described in our previous study (Cao et al., 2007), in some experiments, coverslips were removed from the recording chamber after the outside-out configuration was obtained to check the spontaneous channel activity. Recording pipettes were pulled from borosilicate glass (World Precision Instruments) and had resistances of $10-20 \mathrm{M} \Omega$ for single-channel recording and 2-4 $\mathrm{M} \Omega$ for whole-cell recording. The usual holding potential was $-60 \mathrm{mV}$ for whole-cell and $-100 \mathrm{mV}$ for single-channel recording. The basic extracellular solution contained (mM) $147 \mathrm{NaCl}, 2 \mathrm{KCl}, 1 \mathrm{CaCl}_{2}, 1 \mathrm{MgCl}_{2}, 10$ HEPES, and 13 glucose. When a high concentration of $\mathrm{Na}_{2} \mathrm{ATP}$ was used, the $\mathrm{pH}$ was corrected with $\mathrm{NaOH}$, and the $\mathrm{NaCl}$ content was adjusted to maintain the sodium concentration. The intracellular (pipette) solution comprised of (mM) $147 \mathrm{NaF}, 10$ HEPES, and 10 EGTA (Ding and Sachs, 1999a). All solutions were maintained at $\mathrm{pH} 7.3$ and $300-315 \mathrm{mOsm} / \mathrm{L}$. Chemicals were purchased from Sigma.

Currents were recorded with a patch-clamp amplifier (Axopatch 200B) using pClamp 9 software (Molecular Devices). Data were low-pass filtered at $3 \mathrm{kHz}$ with an 8-bessel filter (LHBF-48X, NPI) and digitized at $10 \mathrm{kHz}$ (single channel) or $1 \mathrm{kHz}$ (whole cell). For single-channel recordings, low ATP concentrations were used (typically 0.3 to $3 \mu \mathrm{M}$ ), and overlapping opening events were rarely observed. For whole-cell recording, between $50 \%$ and $80 \%$ of the series resistance was electronically compensated to minimize voltage errors. A voltage ramp $(-150 \mathrm{mV}$ to $+150 \mathrm{mV}$ in $200 \mathrm{~ms}$ ) was applied every $1 \mathrm{~s}$ from a holding potential of $-60 \mathrm{mV}$. Current-voltage $(I-V)$ relations were obtained from the currents measured during the linear voltage ramp. Rectification is reported as the ratio of the current observed at +150 or $-150 \mathrm{mV}$ to the value computed by linear extrapolation of the $I-V$ relation between +5 and -5 $\mathrm{mV}$. For a linear $I-V$ relation, these values would be unity: wild-type P2X2 channels show modest inward rectification for inward currents (ratio, $\sim 2$ ) and strong inward rectification for outward currents (ratio, $\sim 0.2$ ). Concentration-response curves for ATP were generated using the RSC200 rapid perfusion system (Biologic).

Data analysis. Electrophysiological measurement data were analyzed using QuB program (www.qub.buffalo.edu) and Clampfit 9 software (Axon Instruments). In most experiments, low concentrations of ATP $(0.3-3 \mu \mathrm{M})$ were applied so as to obtain single-channel openings. Open current levels were designated as flickery when no stable openings were resolved by eye at $10 \mathrm{kHz}$ sampling and when the fit of the all-points histogram to two Gaussians was not better than the fit to one Gaussian. Unitary current amplitudes were measured by all-points amplitude histograms fit to two Gaussian distributions. In other experiments, we applied higher concentrations $(30-100 \mu \mathrm{M})$ of ATP and observed single-channels events as the current desensitized during 10 to $20 \mathrm{~s}$ of application. These two methods showed no difference in the singlechannel amplitudes. Results are presented as mean \pm SEM. Tests for statistical significance were performed using nonparametric ANOVA. Concentration-response curves were generated for all the mutations studied. They were fitted to $I=I_{\max } /\left[1+\left(\mathrm{EC}_{50} /[A]\right)^{n}\right]$, where $I$ is the current (maximal value, $I_{\max }$ ), $[A]$ is the agonist concentration, and $\mathrm{EC}_{50}$ is the concentration of agonist needed to evoke a half-maximal current.

\section{Results}

Excised patch recordings showed that mutations introduced into the central region of TM2 ( $\mathrm{Asn}^{333}$ to $\mathrm{Ser}^{340}$ ) often had the effect of producing spontaneous channel activity in the absence of any added ATP (Cao et al., 2007): examples are shown in Figure 2. Such spontaneous activity was never observed in patches from cells expressing wild-type channels. This spontaneous activity continued when the excised patch was well removed from any other cells that might serve as a source of ATP. For each mutation studied, the amplitudes of spontaneous and ATP-evoked currents appeared similar (e.g., T336C in Fig. 2), although there were 

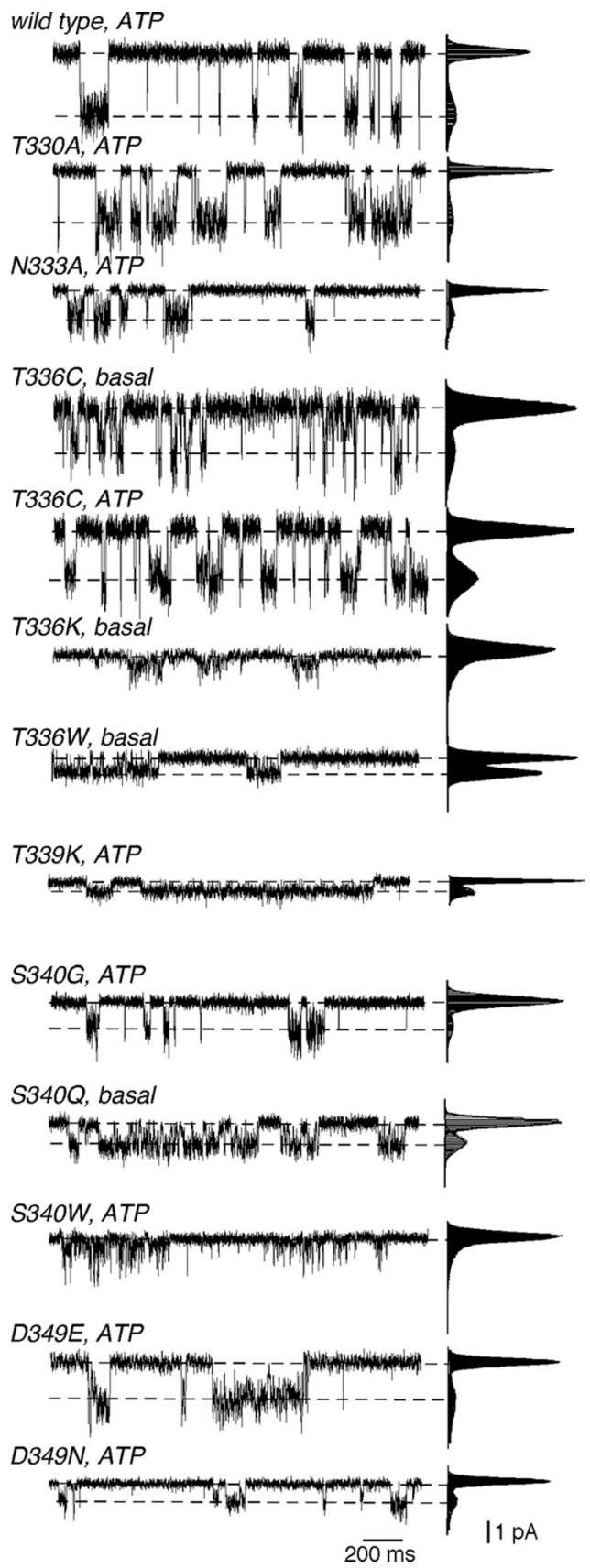

Figure 2. Examples of unitary currents in mutated $\mathrm{P} 2 \mathrm{X}_{2}$ receptors. In each trace, outside-out recording is shown to the left. At the right are shown all-points histograms from longer periods of recording (at least 30 opening events). The vertical axis is the current level with the same scale as the current traces to the left. The horizontal axis is the point count, with a scale range for the open state of $1000-10,000$ points. The distribution was fitted by the sum of two Gaussians, and the peaks of these fits were used to estimate unitary current amplitudes. Some examples show spontaneously opening channels in the absence of ATP (basal). Others show activity evoked by adding ATP [concentrations were as follows (in $\mu \mathrm{M}$ ): wild type, 0.3; T330A, 1; N333A, $0.3 ;$ T336C, 0.3; T339K, 0.3; S340G, 1; S340W, 3; D349E, 1; D349N, 10].

some cases where ATP did not further increase channel activity (supplemental Table 1, available at www.jneurosci.org as supplemental material). Having first observed such spontaneous activity in excised patches, we chose to quantify it by measuring the holding current at $-100 \mathrm{mV}$ in the whole-cell configuration, recorded within $10 \mathrm{~s}$ of break-in. For cells expressing only GFP, and for cells expressing GFP and wild-type P2X2 channels, these values were, respectively, $2.0 \pm 0.3(n=6)$ and $2.2 \pm 0.2(n=33)$ pA/pF (Fig. 3).

\section{Inward current in the absence of ATP}

At $\mathrm{Asn}^{333}$, any negatively charged or polar residue was tolerated. Asp, Glu, Gln, Ser, or Thr did not cause spontaneous opening, and the channel responded normally to ATP. However, other residues (Ala, Cys, Lys, Arg, Trp, Tyr) resulted in spontaneously active channels (Fig. 3). Further into TM2, we found that almost all substitutions at $\mathrm{Thr}^{336}$ destabilized the channel and caused pronounced spontaneous opening (Figs. 2, 3); indeed, this was observed even with simple side-chain removal (T336G) (Fig. 2). The degree to which this occurred was similar for positively charged, negatively charged, uncharged polar, or bulky substitutions; only Ala and Ser did not cause any spontaneous activity when introduced at $\mathrm{Thr}^{336}$ (Fig. 3).

Passing along TM2, the next polar residue is $\mathrm{Thr}^{339}$. Two substitutions here (T339S and T339G) have previously been shown to result in basal channel opening (Cao et al., 2007). We determined that this effect was rather specific; although Cys and Trp (Fig. 3) caused small increases in standing inward current, the introduction of a wide range of other residues did not cause spontaneous activity (Fig. 3 ).

At $\mathrm{Ser}^{340}$, spontaneous channel opening was pronounced with acidic (S340D, S340E), basic (S340K), or acid amide (S340N, S340Q) substitutions (Figs. 2, 3), but such spontaneous activity was not observed by introduction of smaller neutral or polar side-chains (S340A, S340C, S340G, S340T) or large aromatic side-chains (S340W, S340Y). It was striking that substitutions in other parts of TM2 (e.g., $\mathrm{Thr}^{330}, \mathrm{Gly}^{344}, \mathrm{Ser}^{345}$, Cys ${ }^{348}$, $\mathrm{Asp}^{349}$ ) did not cause spontaneous activity, including bulky amino acids such as Trp (Fig. 3).

\section{Unitary currents}

Where amino acid side-chains are exposed within the permeation pathway, one might expect certain substitutions to alter the amplitude of the unitary currents (Hille, 2001). At the outer end of TM2, we found that substitutions at $\mathrm{Thr}^{330}$ bearing a fixed charge completely prevented channel activity evoked by ATP (Fig. 4). Other amino acids, including tryptophan and tyrosine, were tolerated without any apparent change in phenotype (unitary conductance, maximal current, $\mathrm{EC}_{50}$ for ATP) (e.g., T330A) (Fig. 2).

For $\mathrm{Asn}^{333}$, unitary currents were observed for all the substitutions examined. Substitutions that conserved the polar features of asparagine (N333D, N333E, N333Q, N333S, N333T) resulted in channels that were not different from wild-type $\mathrm{P} 2 \mathrm{X}$ receptors, except for minor $(<5$-fold) increases in sensitivity to applied ATP (supplemental Table 1, available at www.jneurosci.org as supplemental material). For N333A, N333C, N333W, and N333Y (which showed standing inward currents without ATP), there were no obvious differences between the unitary currents that occurred spontaneously and those evoked by ATP (e.g., N333A). However, positively charged side-chains (N333R and $\mathrm{N} 333 \mathrm{~K}$ ) gave spontaneously occurring channel openings with reduced unitary conductance ( $\sim 50 \%$ of wild type) (Fig. 4 ), and ATP did not evoke any further activity.

$\mathrm{P}_{2} \mathrm{X}_{2}[\mathrm{~T} 336 \mathrm{C}]$ has been widely studied as a reporter mutation, because ATP-evoked currents are blocked by external methanethiosulfonates: the block is almost complete for positively charged 2-aminoethyl methanethiosulfonate (MTSEA) and 2-(trimethylammonium)ethyl methanethiosulfonate (MTSET), and $\sim 50 \%$ for the negatively charged 2-sulfonatoethyl methanethiosulfonate (MTSES) (Rassendren et al., 1997; Stoop et al., 


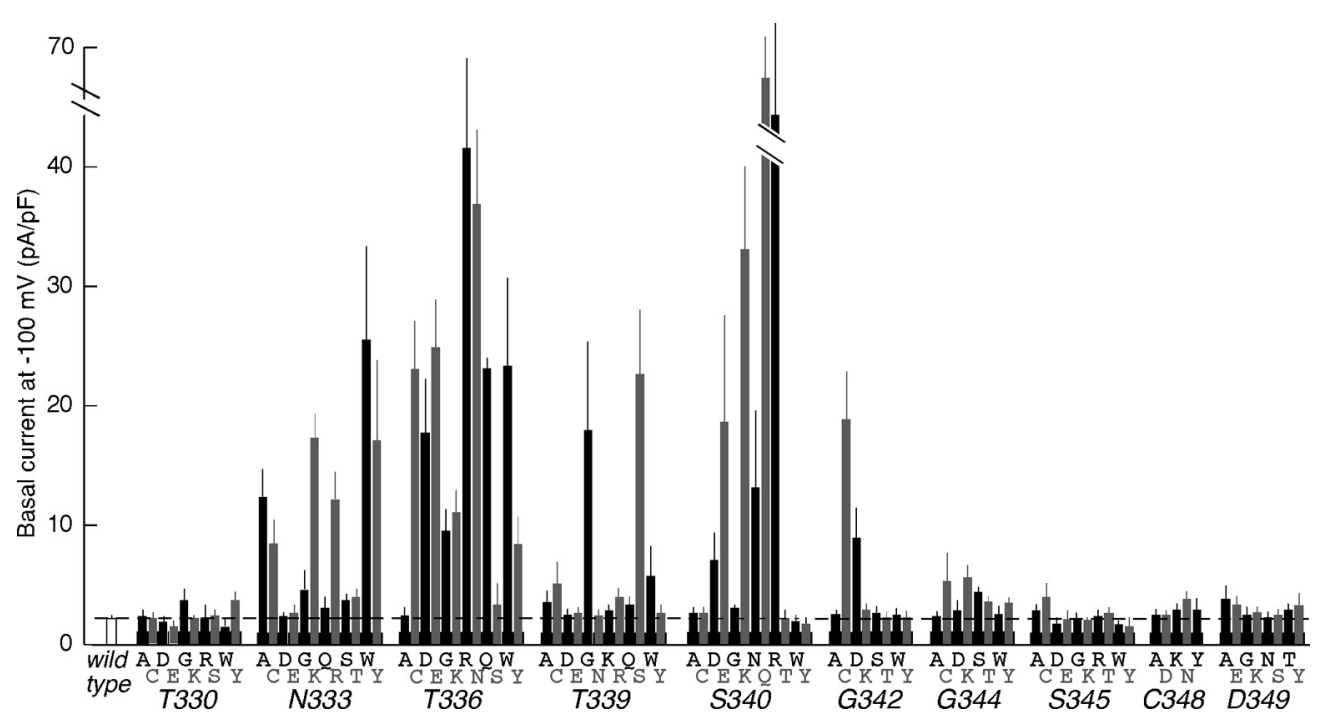

Figure 3. Standing inward currents observed for P2X2 receptors with amino acid substitutions in TM2. Ordinate shows mean holding current (at $-100 \mathrm{mV}$ ) in cells expressing the point mutation shown on the abscissa. Broken line is wild-type level. Bars are SEM for 5-11 observations, except 33 for wild type.

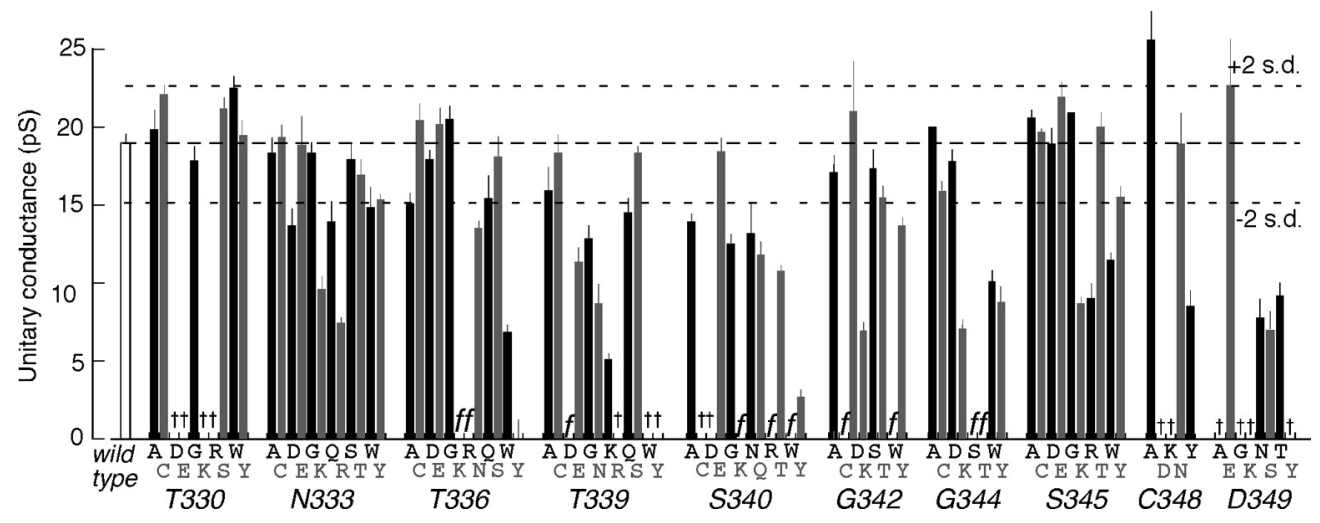

Figure 4. Unitary conductance of ATP-evoked currents in excised patches, for P2X channels with single amino substitutions in TM2.f, Too flickery for unitary currents to be resolved. $\dagger$, No current or very small current evoked by ATP (excised patch or whole-cell recording). In those cases where spontaneously occurring unitary currents were resolved (Fig. 2), the application of ATP increased open probability but did not obviously change unitary current amplitudes. In other cases (for N333K, N333R, T336D, T336E, T336N, T336Q, T336W, S340E, S340K, S340N, S3430Q), where there was no response to ATP, the unitary current amplitudes are from spontaneously occurring openings. Conductance was estimated from all-points histograms at $-100 \mathrm{mV}$. Bars are SEM from 5 to 12 patches in each case.

1999). In the present work, we found that $\mathrm{P}_{2} \mathrm{X}_{2}[\mathrm{~T} 336 \mathrm{C}]$ showed spontaneous unitary currents and that ATP further increased their activity (Fig. 2). MTSEA also evoked a further sustained inward current (Fig. 5A) [similar to the effect previously reported by Rassendren et al. (1997)], while at the same time blocking any ATP-evoked current. Unitary currents were of normal amplitude for other substitutions at $\mathrm{Thr}^{336}$, except for T336W (much reduced), T336Y (no detectable current), and T336K (small, flickery basal openings but no response to ATP) (Figs. 2, 4).

Most substitutions at $\mathrm{Thr}^{339}$ reduced the unitary current amplitudes (e.g., Glu, Gly, Asn, Lys; not resolved for Trp, Tyr, Asp) (Fig. 4), but they were of normal amplitude for Ala, Cys, Gln, and Ser substitutions. At Ser ${ }^{340}$, the amplitudes of the unitary currents were essentially normal for substitutions of similar size (Ala, Gly, and Thr) but much reduced in the case of Tyr (Fig. 4). We could not observe unitary currents for S340C, and currents were too flickery to resolve in the case of S340K and S340W. The residues at 342 and 344 are Gly or Ala in all P2X receptors (Fig. 1): these positions were tolerant of charged (Asp, Lys) or bulky (Tyr) side-chains (Fig. 4). Deeper within TM2, we found that Ser $^{345}$ was tolerant of a wide range of substitutions without any consistent effects on unitary currents. The highly conserved residue at Asp ${ }^{349}$ could be replaced only by Glu or by polar residues (Asn, Ser, Thr).

\section{Outward rectification}

Inward currents pass more readily than outward currents through wild-type P2X2 receptors (Brake et al., 1994; Valera et al., 1994; Evans et al., 1996). This inward rectification is variable from cell to cell (Evans et al., 1996) and is less at higher expression densities

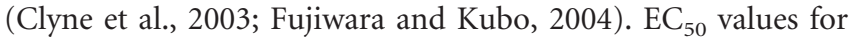
ATP also vary up to sixfold with expression level (Clyne et al., 2003). Therefore, we transfected cDNA concentrations that resulted in small maximal currents at $24-48 \mathrm{~h}$ and used ATP concentrations close to the $\mathrm{EC}_{50}$. Unitary currents showed similar rectification, in confirmation of earlier work (Zhou and Hume, 1998; Ding and Sachs, 1999a,b).

For three central positions in TM2 $\left(\mathrm{Thr}^{336}, \mathrm{Thr}^{339}\right.$, and $\mathrm{Ser}^{340}$ ), the introduction of a positively charged side-chain caused a striking change in the current-voltage relation, with marked outward rectification at positive potentials (Figs. 5-8). No such effects were observed for $\mathrm{Thr}^{330}, \mathrm{Asn}^{333}, \mathrm{Gly}^{342}$, Gly ${ }^{344}$, $\mathrm{Ser}^{345}$, Cys ${ }^{348}$, or Asp ${ }^{349}$. The rectification was always monopha- 
a

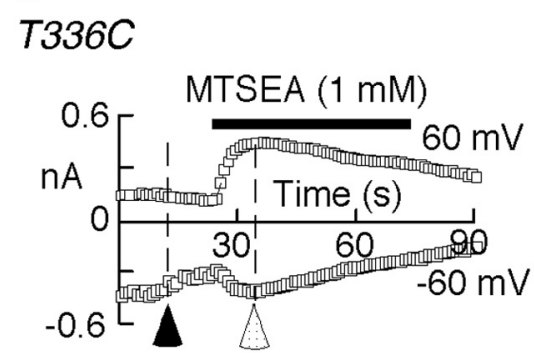

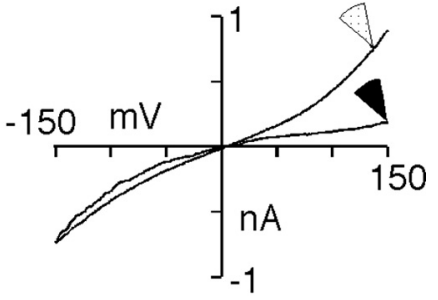

b

T336R

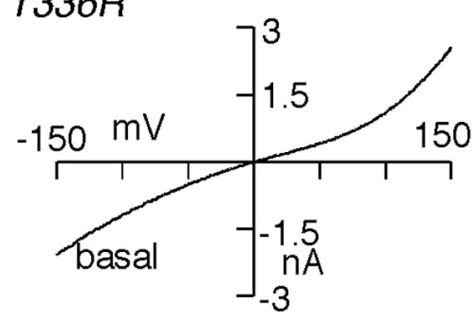

T336K

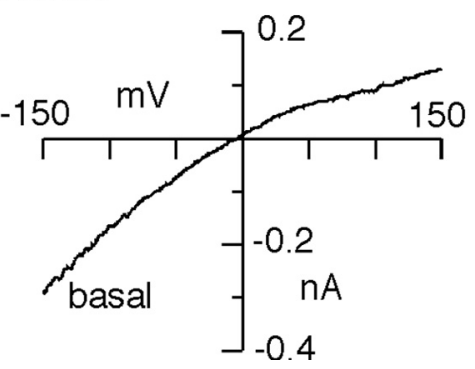

Figure 5. Rectification introduced by substitutions at Thr ${ }^{336}$. $\boldsymbol{a}$, Left, Time course of currents measured at $-60 \mathrm{mV}$ and +60 $\mathrm{mV}$ in T336C. Right, Current-voltage relation from voltage ramps applied at the times indicated by the arrowheads. The basal current of T336C shows similar inward rectification to wild-type channels (filled arrowhead), but after MTSEA (1 mm, solid bar), the current shows marked outward rectification at positive potentials (open arrowhead). $\boldsymbol{b}$, Left, T336R shows large basal current activity, with marked outward rectification. Right, Outward rectification is much less in T336K.

sic (i.e., a progressive increase or decrease in conductance over the entire inward or outward voltage range) and well fitted by a double Boltzmann expression (data not shown). We have, therefore, quantified the rectification from the ratio of the current measured at $150 \mathrm{mV}$ (outward) or $-150 \mathrm{mV}$ (inward) to the current predicted at these potentials by linear extrapolation of the $I-V$ plot from the region -5 to $+5 \mathrm{mV}$. For wild-type $\mathrm{P}_{2} \mathrm{X}_{2}$ receptors, measured at $-150 \mathrm{mV}$ (see Materials and Methods), the ATP-induced current showed approximately twofold inward rectification at negative potentials (ratio, $1.8 \pm 0.1 ; n=6$ ) and fourfold inward rectification at rectification at positive potentials (ratio, $0.3 \pm 0.03 ; n=6$ ).

For positive substitutions at $\mathrm{Thr}^{336}$, the outward rectification was greater with arginine or histidine than with lysine, and it was also marked when MTSEA or MTSET (though not MTSES) was applied to channels with cysteine introduced at this position (Fig. 5). This effect of extracellular MTSET was not observed with intracellular application ( $1 \mathrm{~mm}, 8 \mathrm{~min})$.

T339K (Fig. 6) and S340K (Fig. 7) showed similar outward rectification. Further experiments (summarized in Fig. 8) showed that (1) the effect of lysine was mimicked by arginine and histidine and by positively charged methanethiosulfonates applied to the cysteine-substituted channels (Figs. 6-8); (2) the outward rectification was not dependent on extracellular calcium or magnesium (Figs. 7, 8) or the intracellular or extracellular proton concentration ( $\mathrm{pH}$ was changed by up to three log units in either direction; data not shown); and (3) the outward rectification in T339K was clearly observable at the single-channel level (Fig. 7a). These results strongly suggest that the side-chain charge introduced at these three positions directly influences ion permeation. There were no differences in rectification with any substitutions tested at $\mathrm{Asn}^{333}$ or $\operatorname{Ser}^{345}$ (Fig. 8).

\section{Discussion}

\section{Spontaneous opening}

A striking finding of the present work was the observation by outside-out patch recording of spontaneously active channels when substitutions were introduced into a restricted segment of TM2 (Asn ${ }^{333}$ to $\operatorname{Ser}^{340}$ ) (Fig. 3). The unitary currents always had the same amplitude as those elicited by ATP, and the spontaneous wholecell current also had a current-voltage relation similar to that evoked by ATP; we, therefore, consider that the standing current arose from spontaneously active $\mathrm{P} 2 \mathrm{X}$ receptors, rather than a secondary effect on, for example, the changed expression of another type of ion channel. Our measurement of the standing whole-cell current soon after break-in might fail to resolve very low levels of spontaneous activity.

In the first case of $\mathrm{Asn}^{333}$, normal gating was maintained so long as the sidechain had the polar or negative features of Asn; thus, Asp, Glu, Gln, Ser, and Thr all retained normal gating, whereas introduction of Ala, Cys, Gly, Lys, Arg, Trp, and Tyr resulted in spontaneous opening. This finding might indicate, for example, that the hydroxyl group at his position is important to stabilize the normal closed state of the channel. In the case of $\mathrm{Thr}^{336}$, spontaneous activity resulted from all substitutions tested except those most similar to Thr in side-chain volume (i.e., Ser and Ala). This suggests that steric considerations are important and that $\mathrm{Thr}^{336}$ lies in a tightly packed region of the protein. In contrast, $\mathrm{Thr}^{339}$ and $\mathrm{Ser}^{340}$, which lie at the next turn of the TM2 helix, could tolerate large residues or side-chains bearing a fixed charge without destabilizing the closed state or greatly altering the effectiveness of ATP to open the channel. These effects seem likely to be specific to a particular subtype of $\mathrm{P} 2 \mathrm{X}$ receptor, given that both $\mathrm{Thr}^{336}$ and $\mathrm{Thr}^{339}$ show little absolute conservation among the extended family (Fig. 1).

The Gly residues at 342 and 344 (Fig. 1) were also tolerant of charged (Asp, Lys) or bulky (Tyr, Trp) side-chains (Fig. 4). The first of these glycines is very highly conserved (Fig. 1) and corresponds to $\mathrm{Gly}^{347}$ of the rat $\mathrm{P} 2 \mathrm{X} 4$ receptor, at which position the introduction of Lys or Tyr strongly alters the kinetic behavior and $\mathrm{N}$-methyl-D-glucamine permeability of P2X4 receptors (Khakh et al., 1999). The second Gly has been implicated in the additional increase in conductance of $\mathrm{P} 2 \mathrm{X}$ receptors that occurs with hyperpolarization (Zhou and Hume, 1998; Nakazawa and Ohno, 2005; Fujiwara et al., 2009). Fujiwara et al. (2009) found that this increase occurred much more rapidly in P2X2 [G344A] and suggested that the glycine at this position allowed TM2 to kink under the effect of an applied voltage. Our findings suggest that the flexibility of these glycines is not a critical structural requirement for normal gating, although it could influence the adoption of "additional" open states.

\section{Unitary currents}

At Thr ${ }^{330}$, at the outer end of TM2, fixed charges of either polarity prevent any ATP-evoked current, but no other substitutions al- 

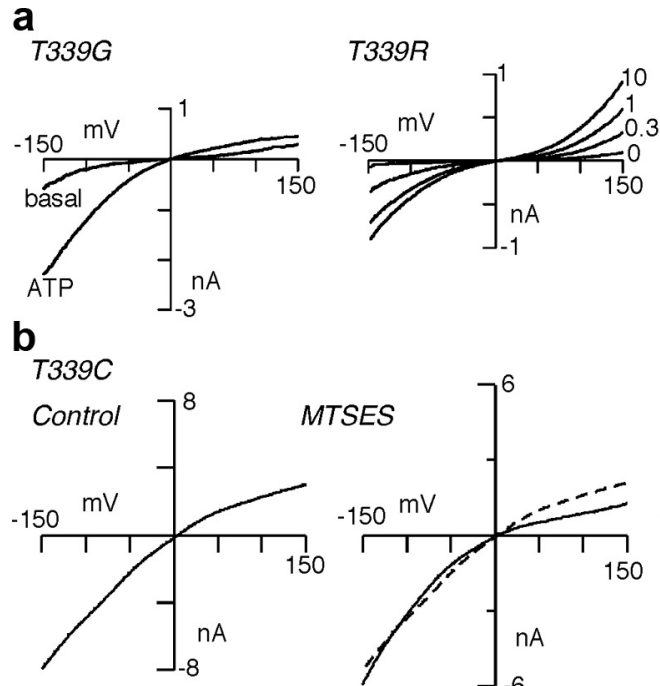
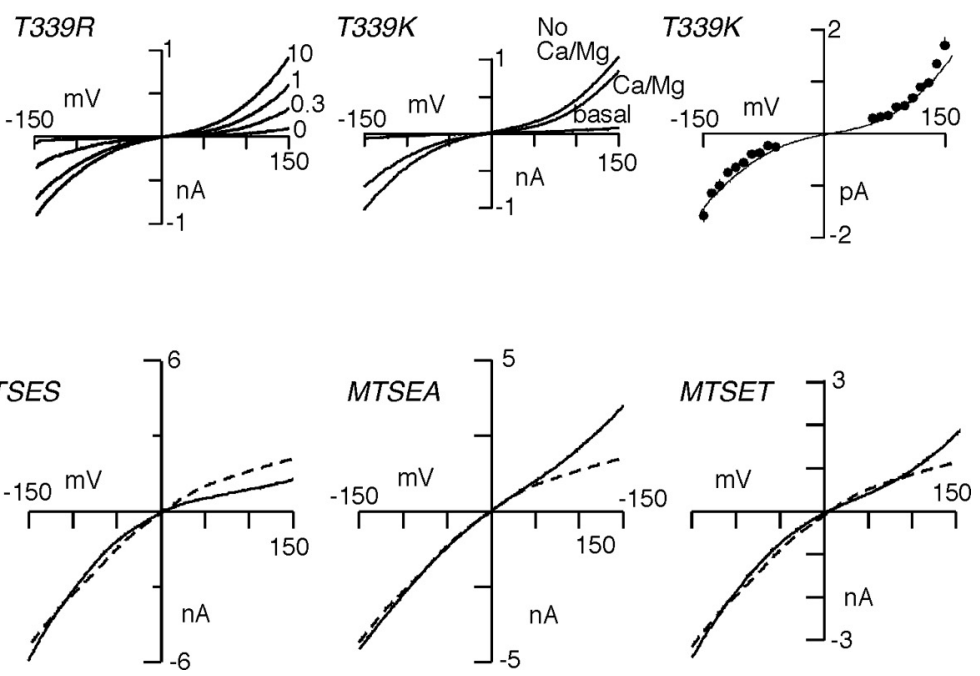

Figure 6. Rectification introduced by substitutions at Thr ${ }^{339} \cdot \boldsymbol{a}$, Left, T339G shows substantial basal current, and this is increased by ATP ( $\left.0.3 \mu \mathrm{m}\right)$. Inward rectification is similar to that seen in wild-type channels. Center-left, T339R shows no basal current (trace labeled 0), but ATP (concentrations indicated, $\mu$ M)-evoked currents showing marked outward rectification at positive potentials. Center-right, T339K shows no basal current, but ATP (10 $\mu \mathrm{m})$-evoked currents showing marked outward rectification at positive potentials. This rectification was unaffected by removal of calcium and magnesium from the external solution ( $\mathrm{No}_{\mathrm{Ca}} \mathrm{Mg}$ ). Right, Unitary currents in T339K show strong rectification both for inward and outward currents. Points are mean amplitudes from seven patches; SEM is less than symbol size. Solid line is scaled whole-cell I-V relation. $\boldsymbol{b}$, Left, T339C currents evoked by ATP ( $3 \mu$ m in each case) show inward rectification at positive potentials similar to see in wild-type receptors. Center-left, This inward rectification is more marked after addition of MTSES (1 mm, 5 min). Center-right and right, The rectification becomes outward after treatment with MTSEA ( $1 \mathrm{~mm}, 5 \mathrm{~min}$ ) or MTSET ( $1 \mathrm{~mm}, 5 \mathrm{~min})$. The broken line in the right three panels is the scaled $I-V$ relation from the left panel.

tered unitary currents (or rectification; see below). In general, the introduction of negative charges into the vestibule of a cation-selective channel might be expected to increase inward current flow (Imoto et al., 1988; Hille, 2001) and the introduction of positive charge to have the opposite effect. Experiments with modification of P2X2[T330C] showed no effect on ATP-induced currents of either positively (MTSET) or negatively (MTSES) charged methanethiosulfonates (Rassendren et al., 1997; Li et al., 2008). Together, these results do not support the view that $\mathrm{Thr}^{330}$ contributes directly to an external vestibule.

At $\mathrm{Asn}^{333}$, introduction of Lys or Arg reduced the unitary conductance to $\sim 50 \%$ of wild-type channels, consistent with earlier studies where MTSET was applied to P2X2[N333C] receptors (Rassendren et al., 1997). No other substitutions tested changed the unitary currents (Fig. 4). Previous measurements of $\mathrm{P}_{\mathrm{Ca}} / \mathrm{P}_{\mathrm{Na}}$ failed to support the interpretation that the polar side-chain of Asn ${ }^{333}$ was an important determinant of calcium permeability (Migita et al., 2001). Together, these results suggest that this residue may lie in an entry vestibule of the open channel, where the addition of net positive charge effectively reduces the concentration of permeant ions.

$\mathrm{Thr}^{336}$, $\mathrm{Thr}^{339}$, and $\mathrm{Ser}^{340}$ become exposed during channel gating as judged by the rate of reactivity of cysteines at these positions (Li et al., 2008). Each was intolerant of large (Tyr, Trp) substituents (Fig. 4). At each position, introduction of a positive charge led to channels with flickery, poorly resolved openings (Figs. 2, 4); this is also consistent with a key role in gating. The
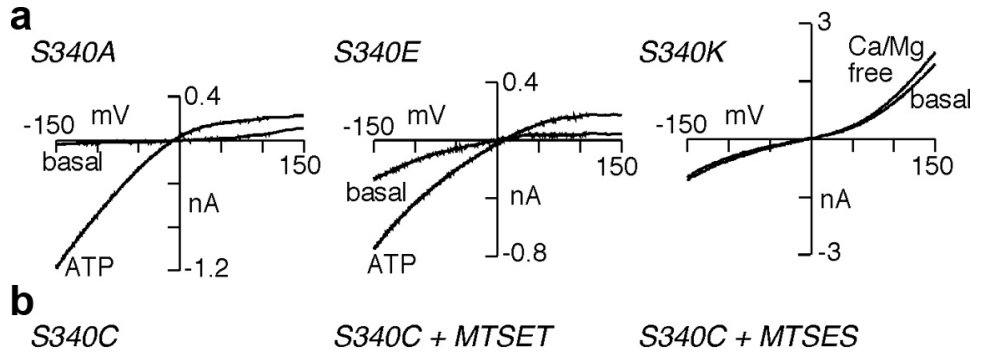

Figure 7. Rectification introduced by substitutions at $\operatorname{Ser}^{340}$. $\boldsymbol{a}$, Left, S340A was similar to wild-type channels; there was minimal basal current, and the current evoked by ATP $(3 \mu \mathrm{m})$ showed typical inward rectification. Center, S340E showed a small basal current and additional current evoked by ATP (30 $\mu \mathrm{m})$. Right, S340K shows outward rectification. This is not different in no extracellular calcium or magnesium. $\boldsymbol{b}$, Left, S340C shows no basal activity, and ATP elicits a current with typical inward rectification. Center, After addition of MTSET, both basal and ATP-evoked currents show marked outward rectification. Right, After addition of MTSES, neither basal nor ATP-evoked current shows outward rectification. ATP (30 $\mu \mathrm{m})$ in each case.

finding that unitary currents were essentially normal with a wide range of substitutions at $\mathrm{Gly}^{342}$, Gly ${ }^{344}$, and $\operatorname{Ser}^{345}$ (Fig. 4) indicate that side-chains of these amino acids are either not exposed to the permeation pathway or are within a relatively wide portion of the channel interior (Fig. 9).

The most highly conserved residue in TM2 is Asp ${ }^{349}$, and there is only one example of a substitution (by Asn in the Ostreococcus receptor) (Fountain et al., 2008). The present work shows that Asn, Ser, and Thr substitutions at this position reduce the unitary conductance by $\sim 50 \%$ but cause no apparent changes in gating or $\mathrm{EC}_{50}$. The critical requirement for a negatively charged or polar side-chain at $\mathrm{Asp}^{349}$ might imply that this residue serves to concentrate cations at the intracellular mouth of the pore, 


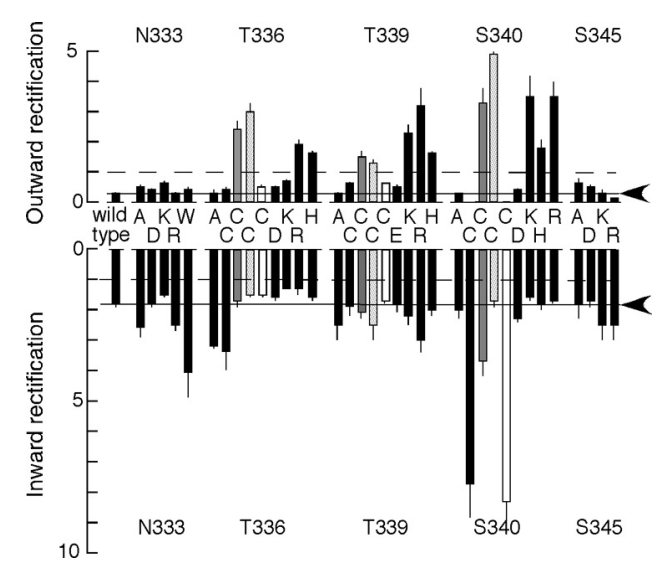

Figure 8. Summary results for mutations causing outward rectification. At $\mathrm{Thr}^{336}, \mathrm{Thr}^{339}$, and $\mathrm{Ser}^{340}$, positively charged residues or positively charged MTS compounds introduced marked outward rectification. Rectification is expressed as the additional current observed at $+150 \mathrm{mV}$ (outward rectification, top) or $-150 \mathrm{mV}$ (inward rectification, bottom) compared with that which would be observed by linear extrapolation of the current-voltage relation from the range -5 to $+5 \mathrm{mV}$; therefore, unity (broken line) indicates no rectification. Solid line and arrowheads indicate rectification in wild-type $P 2 X$ receptors. Filled gray columns, Cysteine substitution after addition of MTSEA. Stippled columns, Cysteine substitution after addition of MTSET. Open columns, Cysteine substitution after addition of MTSES. ATP concentrations were as follows (in $\mu \mathrm{m}$ ): wild-type, 3; N333A, 1; N333D, 3; N333K, 0; N333R, 0; N333W, 1; T336A, 3; T336C, 3; T336K, 0; T336R, 0; T336H, 10; T339A, 1; T339E, 3; T339C, 3; T339K, 1; T339R, 1; T339H, 3; S340A, 10; S340C, 30; S340D, 0; S340H, 0; S340K, 0; S340R, 0; S345A, 10; S345D, 10; S345K, $10 ; S 345 R, 10$. Where the concentration is indicated as zero, the rectification of the "standing" current introduced by the substitution is presented.

although a key role in subunit assembly has also been shown (Duckwitz et al., 2006).

\section{Rectification}

The poor ability of $\mathrm{P} 2 \mathrm{X}$ receptors to pass outward currents reflects intrinsic properties of the permeation pathway rather than block by intracellular cations, such as polyamines or magnesium ions (Evans et al., 1996; Zhou and Hume, 1998; Ding and Sachs, 1999). Our mutations identify a short segment of TM2, including $\mathrm{Thr}^{336}$, $\mathrm{Thr}^{339}$, and $\mathrm{Ser}^{340}$ as the main contributor to this rectification, suggesting the interaction of permeating cations with charges introduced in the permeation pathway. In each case, introduction of a positive charge by direct substitution (i.e., Arg, Lys, His) added a strong outward rectification to the inward rectification normally found in wild-type P2X receptors. We found the same result by adding a positive methane sulfonate in the case of cysteine substitution at these positions, which reduces the likelihood that the results are due to nonspecific structural effects or altered expression levels of the mutated channels (Fujiwara and Kubo, 2004).

At $\mathrm{Thr}^{336}$, Lys was ineffective, whereas Arg, His, Cys plus MTSET, and Cys plus MTSEA were all effective to reverse inward rectification. However, for $\mathrm{Thr}^{339}$ and $\mathrm{Ser}^{340}$, all positive charges much increased outward currents through the P2X receptor channel, whether by His, Arg, or Lys substitution or by addition of positive methane thiosulfonates combined with cysteine substitution (Figs. 5, 8). The difference might indicate that the open channel is relatively wider at this position at the level of $\mathrm{Thr}^{336}$, given that the side-chain of lysine is shorter than that of the other substitutions. Overall, these findings are reminiscent of ionotropic glutamate receptors, where outward current is increased when Arg occupies a key position within the permeation pathway (the QRN site) rather than the Gln or Asn that can result from RNA editing at this position (Sommer et al., 1991).
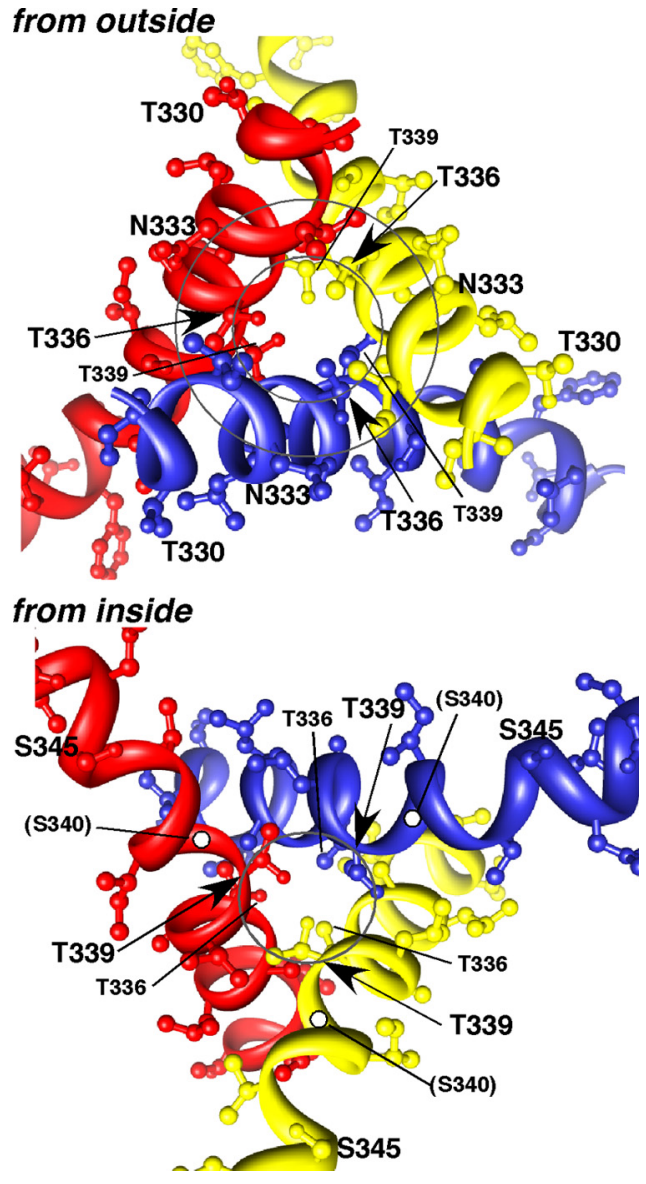

Figure 9. Model of three TM2 helices to illustrate positions of key residues. Viewed from the outside, the circles pass through the $C \alpha$ atoms of Asn ${ }^{333}$ (outer circle) and Thr ${ }^{336}$ (inner circle) from each chain. Viewed from the inside, the circle passes through the $C \alpha$ atoms of $\operatorname{Thr}^{339}$. The structure shown is a threaded model of rat P2X2 generated using a default script in Modeler9v6 from the zebrafish P2X4 receptor in the closed state (pdb 3H9V) (Kawate et al., 2009) and indicating side-chains from Asn ${ }^{333}$ to $\mathrm{Ser}^{340}$ only. The side-chain of $\mathrm{Ser}^{340}$ is not seen, but the position of $\operatorname{Ser}^{340}\left(\alpha\right.$ is indicated (white dots). The results indicate that $\operatorname{Ser}^{340}$ is exposed in the open channel permeation pathway, which implies that the three TM2 helices twist counterclockwise during channel opening.

\section{Structural considerations}

Figure 9 shows a model of the three TM2 helices of that rat P2X2 receptor based on the crystal structure of the zebrafish P2X4.1 receptor (in the closed state) (Kawate et al., 2009). Asn ${ }^{333}$ and $\mathrm{Asp}^{349}$ in the inner and outer vestibules, respectively, correspond to $A s n^{341}$ and $\mathrm{Asp}^{357}$ of the zebrafish sequence. The residues of the zebrafish receptor that correspond in position to $\mathrm{Thr}^{336}$, $\mathrm{Thr}^{339}$, and $\mathrm{Ser}^{340}$ are actually not polar $\left(\mathrm{Ala}^{344}, \mathrm{Ala}^{347}, \mathrm{Leu}^{348}\right)$; indeed, they are not polar in most other $\mathrm{P} 2 \mathrm{X}$ receptor sequences (Fig. 1). Kawate et al. (2009) proposed that the zebrafish receptor is closed by an occlusion provided by the "slab of packed protein" extending from $\mathrm{Leu}^{340}$ (= = Ile ${ }^{332}$ in P2X2) to $\mathrm{Ala}^{347}$ (= $\mathrm{Thr}^{339}$ in $\mathrm{P} 2 \mathrm{X} 2$ ). Our finding that many substitutions at $\mathrm{Asn}^{333}, \mathrm{Thr}^{336}$, and $\operatorname{Ser}^{340}$ (Fig. 3) strongly destabilize the channel closed state agree well with this proposal. In the rat P2X2 model, the closest associations between the three helices occur at the levels of Thr ${ }^{336}$ and $\mathrm{Thr}^{339}$. Our conclusions on the role of $\mathrm{Asn}^{333}$ and Asp ${ }^{349}$ from mutagenesis are consistent with the suggestion from the crystal structure that these residues may serve to concentrate cations in the outer and inner vestibules.

Our observations of the properties of the open channel (unitary currents, outward rectification resulting from positively 
charged substitutions) allow us to suggest that the open channel widens at $\mathrm{Thr}^{336}$ and $\mathrm{Thr}^{339}$ and that these residues now provide the "selectivity filter." Moreover, the side-chain at Ser $^{340}$ (which is turned away from the central axis in the closed channel) now influences these properties. This implies that the TM2 helices rotate anticlockwise by several tens of degrees, as they slide against each other and separate during channel opening. The mechanism accords with the earlier finding that $\mathrm{P} 2 \mathrm{X} 2$ receptor channel opening is prevented when $\operatorname{Ile}^{328}$ (at the outer end of TM2) is tethered by an engineered disulfide to $\mathrm{Val}^{48}$ in TM1 (Jiang et al., 2001). It is not dissimilar in principle from the opening mechanisms believed to pertain for tetrameric potassium channels (Perozo et al., 1999) and pentameric nicotinic acetylcholine receptors (Unwin, 1995) or mechanosensitive MscL channels (Sukharev et al., 2001). In the case of the trimeric P2X receptor, one might conjecture that such a conformational change underlying channel opening could in some circumstances allow further widening to occur and in this way form a conducting pathway that is permeant to even larger ions such as $N$-methyl-D-glucamine and propidium.

\section{References}

Brake AJ, Wagenbach MJ, Julius D (1994) New structural motif for ligandgated ion channels defined by an ionotropic ATP receptor. Nature 371:519-523.

Cao L, Young MT, Broomhead HE, Fountain SJ, North RA (2007) $\mathrm{Thr}^{339}$ to-serine substitution in rat $\mathrm{P}_{2} \mathrm{X}_{2}$ receptor second transmembrane domain causes constitutive opening and indicates a gating role for Lys ${ }^{308}$. J Neurosci 27:12916-12923.

Clyne JD, Brown TC, Hume RI (2003) Expression level dependent changes in the properties of $\mathrm{P}_{2} \mathrm{X}_{2}$ receptors. Neuropharmacology 44:403-412.

Ding S, Sachs F (1999a) Single channel properties of P2X $\mathrm{X}_{2}$ purinoceptors. J Gen Physiol 113:695-720.

Ding S, Sachs F (1999b) Ion permeation and block of $\mathrm{P}_{2} \mathrm{X}_{2}$ purinoceptors: single channel recordings. J Membr Biol 172:215-223.

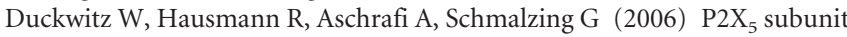
assembly requires scaffolding by the second transmembrane domain and a conserved aspartate. J Biol Chem 281:39561-39572.

Egan TM, Haines WR, Voigt MM (1998) A domain contributing to the ion channel of ATP- gated $\mathrm{P}_{2} \mathrm{X}_{2}$ receptors identified by the substituted cysteine accessibility method. J Neurosci 18:2350-2359.

Evans RJ, Lewis C, Virginio C, Lundstrom K, Buell G, Surprenant A, North RA (1996) Ionic permeability of, and divalent cation effects on, two ATP-gated cation channels (P2X receptors) expressed in mammalian cells. J Physiol 497:413-422.

Fountain SJ, Cao L, Young MT, North RA (2008) Permeation properties of a P2X receptor in the green algae Ostreococcus tauri. J Biol Chem 283:15122-15126.

Fujiwara Y, Kubo Y (2004) Density-dependent changes of the pore properties of the $\mathrm{P}_{2} \mathrm{X}_{2}$ receptor channel. J Physiol 558:31-43.

Fujiwara Y, Keceli B, Nakajo K, Kubo Y (2009) Voltage- and [ATP]dependent gating of the P2X $\mathrm{X}_{2}$ ATP receptor channel. J Gen Physiol 133:93-109.

Hille B (2001) Ion channels of excitable membranes, Ed 3. Sunderland, MA: Sinauer.

Imoto K, Busch C, Sakmann B, Mishina M, Konno T, Nakai J, Bujo H, Mori Y, Fukuda K, Numa S (1988) Rings of negatively charged amino acids determine the acetylcholine receptor channel conductance. Nature 335:645-648.
Jiang LH, Rassendren F, Spelta V, Surprenant A, North RA (2001) Amino acid residues involved in gating identified in the first membranespanning domain of the rat $\mathrm{P} 2 \mathrm{X}_{2}$ receptor. J Biol Chem 276:14902-14908.

Jiang LH, Rassendren F, Mackenzie A, Zhang YH, Surprenant A, North RA (2005) N-methyl-D-glucamine and propidium dyes utilize different permeation pathways at rat $\mathrm{P}_{2} \mathrm{X}_{7}$ receptors. Am J Physiol Cell Physiol 289:C1295-C1302.

Kawate T, Michel JC, Birdsong WT, Gouaux E (2009) Crystal structure of the ATP-gated $\mathrm{P}_{2} \mathrm{X}_{4}$ ion channel in the closed state. Nature 460:592-598.

Khakh BS, North RA (2006) P2X receptors as cell-surface ATP sensors in health and disease. Nature 442:527-532.

Khakh BS, Bao XR, Labarca C, Lester HA (1999) Neuronal P2X transmittergated cation channels change their ion selectivity in seconds. Nat Neurosci 2:322-330.

Li M, Chang TH, Silberberg SD, Swartz KJ (2008) Gating the pore of P2X receptor channels. Nat Neurosci 11:883-887.

Li Z, Migita K, Samways DS, Voigt MM, Egan TM (2004) Gain and loss of channel function by alanine substitutions in the transmembrane segments of the rat ATP-gated $\mathrm{P}_{2} \mathrm{X}_{2}$ receptor. J Neurosci 24:7378-7386.

Migita K, Haines WR, Voigt MM, Egan TM (2001) Polar residues of the second transmembrane domain influence cation permeability of the ATP-gated P2X 2 receptor. J Biol Chem 276:30934-30941.

Nakazawa K, Ohno Y (2005) Characterization of voltage-dependent gating of $\mathrm{P} 2 \mathrm{X}_{2}$ receptor/channel. Eur J Pharmacol 508:23-30.

Nicke A, Bäumert HG, Rettinger J, Eichele A, Lambrecht G, Mutschler E, Schmalzing G (1998) P2X $\mathrm{X}_{1}$ and $\mathrm{P}_{2} \mathrm{X}_{3}$ receptors form stable trimers: a novel structural motif of ligand-gated ion channels. EMBO J 17:30163028.

North RA (2002) Molecular physiology of P2X receptors. Physiol Rev 82:1013-1067.

Perozo E, Cortes DM, Cuello LG (1999) Structural rearrangements underlying $\mathrm{K}^{+}$-channel activation gating. Science 285:73-78.

Rassendren F, Buell G, Newbolt A, North RA, Surprenant A (1997) Identification of amino acid residues contributing to the pore of a $\mathrm{P} 2 \mathrm{X}$ receptor. EMBO J 16:3446-3454.

Silberberg SD, Chang TH, Swartz KJ (2005) Secondary structure and gating rearrangements of transmembrane segments in rat $\mathrm{P}_{2} \mathrm{X}_{4}$ receptor channels. J Gen Physiol 125:347-359.

Sommer B, Köhler M, Sprengel R, Seeburg PH (1991) RNA editing in brain controls a determinant of ion flow in glutamate-gated channels. Cell 67:11-19.

Stoop R, Thomas S, Rassendren F, Kawashima E, Buell G, Surprenant A, North RA (1999) Contribution of individual subunits to the multimeric P2 $\mathrm{X}_{2}$ receptor: estimates based on methanethiosulfonate block at T336C. Mol Pharmacol 56:973-981.

Sukharev S, Betanzos M, Chiang CS, Guy HR (2001) The gating mechanism of the large mechanosensitive channel MscL. Nature 409:720-724.

Surprenant A, Rassendren F, Kawashima E, North RA, Buell G (1996) The cytolytic P2Z receptor for extracellular ATP identified as a P2X receptor $\left(\mathrm{P} 2 \mathrm{X}_{7}\right)$. Science 272:735-738.

Unwin N (1995) Acetylcholine receptor channel imaged in the open state. Nature 373:37-43.

Valera S, Hussy N, Evans RJ, Adami N, North RA, Surprenant A, Buell G (1994) A new class of ligand-gated ion channel defined by $\mathrm{P} 2 \mathrm{x}$ receptor for extracellular ATP. Nature 371:516-519.

Virginio C, MacKenzie A, Rassendren FA, North RA, Surprenant A (1999) Pore dilation of neuronal P2X receptor channels. Nat Neurosci 2: 315-321.

Zhou Z, Hume RI (1998) Two mechanisms for inward rectification of current flow through the purinoceptor $\mathrm{P}_{2} \mathrm{X}_{2}$ class of ATP-gated channels. J Physiol 507:353-364. 